\title{
Rubber Clay Nanocomposites
}

\author{
Maurizio Galimberti
}

Additional information is available at the end of the chapter

http://dx.doi.org/10.5772/51410

\section{Introduction}

RCN Nomenclature and classification of clays are first summarized, highlighting the most important clay features that affect their behaviour as fillers for rubbers. The modification of clays with organophilic compensating cations, to promote their compatibilization with the polymer matrix, is then presented. The processing methods for the preparation of $\mathrm{RCN}$ is then discussed and the main aspects of $\mathrm{RCN}$ are reviewed, namely: rheology, vulcanization, barrier and mechanical properties. Finally, commercial applications of RCN are presented.

A large scientific and patent literature is available on $\mathrm{RCN}$ and it was taken into consideration for the preparation of this Chapter. As the RCN applications are treated as well, press releases and news available on web sites were considered and commercial products were examined. Patents, when cited, are regarded just as publications, without considering if they were already granted or if, viceversa, they are still patent applications. Literature reporting on polymer clay nanocomposites (PCN) is available [1-13] and it has to be considered, to fully understand structure and properties of RCN. Reviews are also available, dealing specifically with rubbers [14-21].

\section{Clays}

\subsection{Nomenclature and classification}

The Joint Nomenclature Committee of the AIPEA (Association Internationale pour l'Etude des Argiles) and the CMS (Clay Minerals Society) say that a clay is a naturally occurring material composed primarily of fine-grained minerals, which is generally plastic at appropriate water contents and hardens when dried or fired. Hence, the definition of clay refers essentially to the macroscopic clay properties. Precisely determined crystallographic structures should be named as clay minerals [22]. 
Clays are layered: this is their most important feature. They are inorganic compounds made by stacked layers, whose atoms are joined together by iono-covalent bonds, that are bound to each other in the perpendicular direction through weaker forces. This implies that layers can be separated from each other by applying a minor amount of energy, whereas remarkable energy is required to break the layers.

Clays are a sub-family belonging to the larger family of layered oxides (or oxyhydroxides). They are not only silicates, as some of them do not contain any silicon atom, though those applied for the preparation of polymer nanocomposites are indeed essentially silicates.

Clays can be classified according to the electrical charge of the layer, as summarized in Table 1. Clays have either (i) neutral layers or (ii) negatively charged layers or (iii) positively charged layers. In the last two cases, the layer charge is exactly compensated by an equal amount of opposite charges located in the interlayer space. Clays with negatively charged layers or positively charged layers are respectively called cationic clays and anionic clays.

\begin{tabular}{|l|l|l|}
\hline Type of layers & Type of clay & Main features \\
\hline $\begin{array}{l}\text { neutral } \\
\text { layers }\end{array}$ & $\begin{array}{l}\text { pyrophyllite, talc, } \\
\text { kaolinite }\end{array}$ & $\begin{array}{l}\text { neutral clays } \\
\text { layers joined together by van der Waals } \\
\text { interactions and/or hydrogen bonds }\end{array}$ \\
\hline $\begin{array}{l}\text { negatively charged } \\
\text { layers }\end{array}$ & $\begin{array}{l}\text { phyllosilicates: } \\
\text { e.g. bentonites } \\
\text { (main component: } \\
\text { montmorillonite) }\end{array}$ & $\begin{array}{l}\text { cationic clays } \\
\text { the negative layer charge is exactly } \\
\text { compensated } \\
\text { by compensating cations are located } \\
\text { in the interlayer space. }\end{array}$ \\
\hline $\begin{array}{l}\text { positively charged } \\
\text { layers }\end{array}$ & $\begin{array}{l}\text { hydrotalcite (HT). } \\
\text { layered double } \\
\text { hydroxides } \\
\text { (HT-like family) }\end{array}$ & $\begin{array}{l}\text { anionic clays } \\
\text { the positive layer charge is exactly compensated } \\
\text { by compensating anions located } \\
\text { in the interlayer space }\end{array}$ \\
\hline
\end{tabular}

Table 1. Classification of clays as a function of the electrical charge of the layer

\subsection{Organization and structure of clays}

Clays give rise to a multiscale organization. Examining the upper level of said organization, clays particles of micrometric size form millimetric-size agglomerates. In a polymer matrix, the dispersion of these agglomerates is one of most important feature of the polymer nanocomposite. Figure 1 reports the structure of a montmorillonite (Mt) (Figure 1a), the most applied clay for the preparation of polymer nanocomposites, thanks to its large availability, low cost and high surface area. Moreover, purified Mt, with less than $1 \%$ of crystalline silica, is considered safe and is handled as a standard powder, as its platy nanoparticles, with only one dimension at the nanoscale, appear to have little chance to cross biological barriers [23]. 


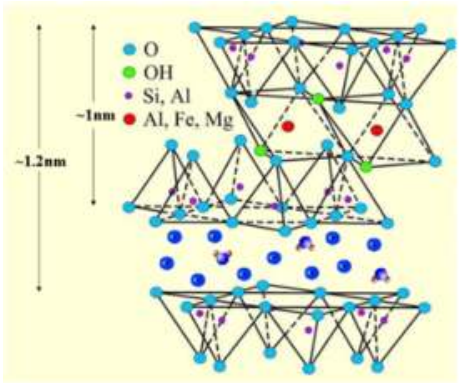

(1a)

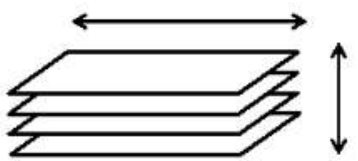

(1b)

Figure 1. Structure of montmorillonite (Figure 1a) and a scheme (Figure 1b) to highlight the significant difference in length with respect to thickness of the layers

By examining a clay such as $\mathrm{Mt}$ at the lower level of its organization, it can be seen that a single clay layer is characterized by lateral dimensions from 100 to $1000 \mathrm{~nm}$ and by a thickness of about 1 nanometer. Mt is a TOT type clay mineral, with two tetrahedral (T) sheets linked to both sides to a central octahedral $(\mathrm{O})$ sheet. These sandwiches are held together by weak interforces and alkaline and alkaline-earth cations are located in the interlayer space. Each silicate layer is terminated on its faces by oxygen atoms and on its periphery by oxygen atoms and hydroxide groups. The hydrophilic nature of Mt implies that a compatibilizer has to be used in order to disperse Mt in a lipophilic matrix, such as the one of most diffused rubbers. To modify a pristine Mt with a compatibilizer, the cations located in the interlayer space are exchanged with organophilic cations, preferentially with long chain quaternary alkyl ammonium cations, an organoclays (OC) are formed [24]. OC are discussed in the next paragraph. The high cationic exchange capacity (CEC) of Mt further pushes its use in polymer nanocomposites.

The term nanocomposites was many times used in previous lines. In fact, nanocomposites are defined as composite materials characterized by the presence of dispersed particles whose size is in the "nanoscale", defined as "having one or more dimensions of the order of $100 \mathrm{~nm}$ or less" [25]. Mt can be considered as a nanomaterial and, as it will be discussed later on, as a nanofiller and its polymer composites are thus nanocomposites.

Figure 1 shows as well a scheme (Figure $1 \mathrm{~b}$ ) that highlights the peculiar shape of the layers, that have a significant difference in length with respect to thickness. Considering Mt as a reinforcing filler, this means that Mt has a high aspect ratio. As it will be discussed in Paragraph 10, the mechanical reinforcement of a polymer matrix strongly depends on the aspect ratio of the filler, i.e. on the ratio between its longest and shortest dimensions. This ratio is often indicated as shape factor $f$. The higher is the shape factor $f$ and the higher are the values obtained for the dynamic-mechanical moduli. It is worth commenting here that to have a high shape factor, the Mt layers have to be brought apart, that means Mt has to be exfoliated. The highest aspect ratio for a clay would be given by the ratio between the longest lateral dimension and the thickness of a single layer. 


\subsection{X-ray diffraction of clays}

Clays are crystalline materials and X-Ray Diffraction (XRD) analysis is a technique largely used to assess clay features. In the Bragg model of X-rays diffraction, that indicates the plane spacing with $d$ index and the plane orientation with three Miller indexes $(h, k, \ell)$, a constructive interference is obtained for X-rays scattered from adjacent planes when the angle $\theta$, between the plane and both the incident and reflected beams, and the plane spacing is related with the X-ray wavelength $\lambda$. through the equation known as the Bragg law [26]:

$$
2 \mathrm{~d} \sin \theta=\mathrm{n} \lambda
$$

From the values of $\theta$ angles detected in the XRD pattern, it is possible to determine clay features such as: dhke interlayer distance, Dhk correlation length in a crystallographic direction, for example in the plane of the layers and in the direction orthogonal to the layers, and hence the number of stacked layers giving rise to a crystalline unit.

Figure 2 shows the XRD patterns of two pristine Mt available in the market: Cloisite ${ }^{\circledR} \mathrm{Na}$ from Southern Clay and Dellite ${ }^{\circledR}$ HPS from Laviosa Chimica Mineraria.
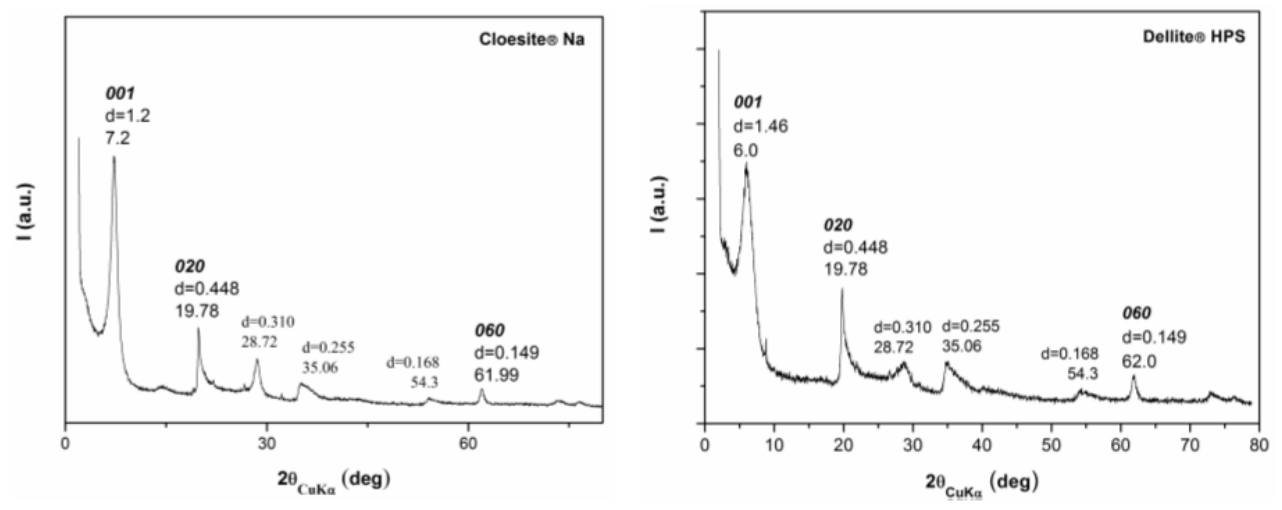

Figure 2. X-Ray diffraction patterns in the 2theta range $0-80^{\circ}$ for pristine Mt samples: Cloisite ${ }^{\circledR} \mathrm{Na}$ and Dellite ${ }^{\circledR}$ HPS

The do01 interlayer distance was determined to be about 1.20 and $1.46 \mathrm{~nm}$ for Cloisite ${ }^{\circledR} \mathrm{Na}$ and Dellite ${ }^{\circledR}$ HPS, respectively. As mentioned above, from XRD data it is also possible to calculate the Dhk correlation length of the crystalline domain in the direction orthogonal to the structural layer, through the Scherrer equation:

$$
\mathrm{D}_{\mathrm{hk} \ell}=0.9 \lambda / \beta_{\mathrm{hk} \ell} \cos \theta_{\mathrm{hk} \ell}
$$

where: $\lambda$ is the wavelength of the irradiating beam (1.5419 $\AA, \mathrm{CuK} \alpha), \beta_{\mathrm{hk} \ell}$ is the width at half height, and $\theta_{\text {hk }}$ is the diffraction angle [27]. With reference to the (001) reflection and by introducing the correction factor, to be used in case $\beta_{\mathrm{hk} \ell}$ is lower than $1^{\circ}$, a Do01 value of about $9 \mathrm{~nm}$ and about $4 \mathrm{~nm}$ was calculated for Cloisite ${ }^{\circledR} \mathrm{Na}$ and Dellite ${ }^{\circledR}$ HPS, respectively. Taking into account that the do01 interlayer distances reported above, a 
number of about 8 and about 4 stacked layers was calculated for Cloisite ${ }^{\circledR} \mathrm{Na}$ and Dellite ${ }^{\circledR}$ HPS, respectively. This elaboration demonstrates that the available pristine Mt are characterized by a pretty typical interlayer distance and by a relatively low number of stacked layers.

\section{Organoclays}

As mentioned in the previous paragraph, OC are prepared through the exchange reaction of a pristine clay with an organophilic ion. In the case of cationic clays, such as Mt, organophilic ammonium cations are mostly used for preparing OC for polymer nanocomposites. The intercalation of ammonium cations leads to an expansion of the

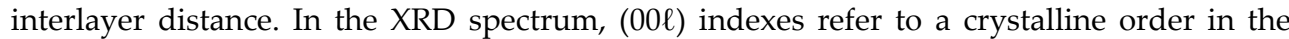
direction perpendicular to the structural layers: the (001) reflection is due to regularly stacked layers and higher order reflections, e.g.. (002) and (003), originate from the regular arrangement of intercalants. An expansion of $d$ interlayer spacing corresponds to a shift of (001) reflection towards lower $2 \theta$ angle values.

Figure 3 shows two types of ammonium ions largely used as Mt compensating cations and the expansion of interlayer distance that occurs as a consequence of their intercalation. The ammonium cations are: dimethyl-talloyl-dihydroxyethyl and dimethylditalloyl and the talloyl (T) group can be optionally hydrogenated (HT).
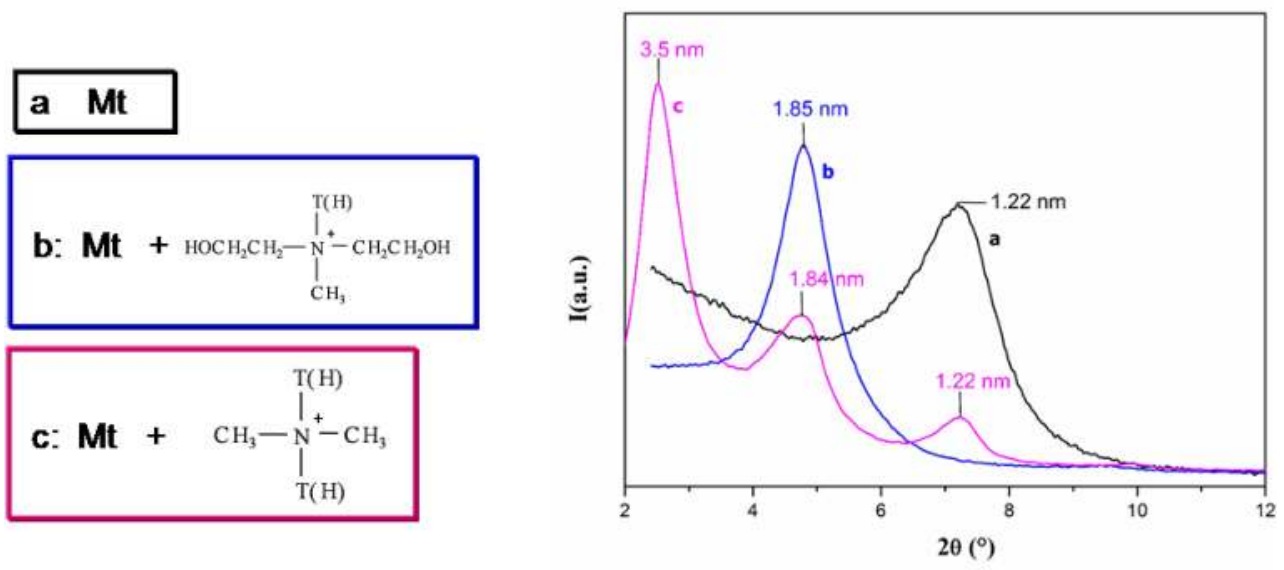

Figure 3. Expansion of Mt interlayer distance as a consequence of ammonium cations intercalation. 2(H)T and (H)Tdihydroxyethyl as the ammonium cations

It is worth underlying that the same ammonium cation can give rise to different interlayer distances, as a function of its weight percent and of its bond with the inorganic layer. In fact the ammonium can be ionically bonded or can be only absorbed on the layer surface. Table 2 reports the values of interlayer distances detected for commercially available OC with 2HT as the compensating ammonium cation. 


\begin{tabular}{|c|c|c|c|c|c|}
\hline Organoclay & $\begin{array}{c}\% \text { wt } \\
\text { organic }\end{array}$ & $2 \theta(\mathrm{deg})$ & $\mathrm{Hkl}$ & $\mathrm{d}(\mathrm{nm})$ & do01 (nm) \\
\hline \multirow{2}{*}{ Dellite ${ }^{\circledR} 72 \mathrm{~T}$} & \multirow{2}{*}{$36-38$} & 3.42 & 001 & 2.59 & \multirow{2}{*}{$\sim 2.5$} \\
\hline & & 7.12 & 002 & 1.24 & \\
\hline \multirow{2}{*}{ Closite ${ }^{\circledR} 20 \mathrm{~A}$} & \multirow{2}{*}{38} & 3.57 & 001 & 2.48 & \multirow{2}{*}{$\sim 2.5$} \\
\hline & & 7.1 & 002 & 1.25 & \\
\hline \multirow{2}{*}{ Closite ${ }^{\circledR} 15 \mathrm{~A}$} & \multirow{2}{*}{43} & 2.98 & 001 & 2.97 & \multirow{2}{*}{$\sim 3.0$} \\
\hline & & 7.15 & $00 ?$ & 1.24 & \\
\hline \multirow{4}{*}{ Dellite ${ }^{\circledR}$ 67G } & \multirow{4}{*}{45} & 2.50 & 001 & 3.53 & \multirow{4}{*}{$\sim 3.6$} \\
\hline & & 4.66 & 002 & 1.89 & \\
\hline & & 7.23 & 003 & 1.22 & \\
\hline & & 9.8 & 004 & 0.90 & \\
\hline
\end{tabular}

Table 2. Organoclays with $2 \mathrm{HT}$ as the compensating ammonium cation

\section{Clays and organoclays used for RCN}

Literature available on $\mathrm{RCN}$ essentially refers to cationic clays. Those used for RCN preparation were: Na-Mt, Na-bentonite, Na-fluorohectorite, rectorite, vermiculite and a fibrillar silicate such as attapulgite. Clays of the bentonite family and, among them, Mt in particular, were the most applied ones. This chapter refers thus to data based on cationic clays. As discussed in paragraphs 2 and 3, a lipophilic compensating cation promotes the compatibilization of the cationic clay with the polymer matrix. Those used for the preparation of $\mathrm{RCN}$ are listed as follows, indicating for the ammonium cation the substituents of the nitrogen atom: (i) cations from primary alkenylamines, (ii) ammonium cations with three methyls and one long chain alkenyl, (iii) ammonium cations with two methyls, an hydrogenated tallow and a benzyl group, (iv) ammonium cations with two methyls and two ethylhexyl or short chain alkenyl groups, (iv) ammonium cations with a methyl, a tallow and polar groups such as 2-hydroxyethyl, (v) ammonium cations with two methyls and two (hydrogenated) tallow groups.

\section{Processing methods for the preparation of $\mathrm{RCN}$}

In this paragraph, distribution and dispersion of clays in a rubber matrix are discussed. They will be shown as depending on the chemical nature of the clay (pristine or organically modified) and on the selection of the appropriate processing technology.

Different methods have been developed for the preparation of RCN. A classification can be attempted, based on the type of clay used for the preparation of the nanocomposite: pristine or organically modified, as it is summarized in Table 3.

A pristine clay can be blended with rubber latexes (NR and E-SBR as the rubbers) through what is known as the emulsion blending. It can also be blended with the rubber in the melt state, performing the exchange reaction with an ammonium salt and using the rubber as the reaction medium. 
For an organically modified clay, melt and solution blending can be applied. In the melt blending, the $\mathrm{OC}$ is mixed directly with the rubber in the melt state. In the solution blending, the rubber is first dissolved in a good solvent, adding the OC swollen in the same solvent.

Methods that use pristine clay and the melt blending of an OC are suitable for an industrial development, whereas the solution blending can be adopted in a laboratory. In this paragraph, the impact of mixing methods on clay distribution and dispersion is examined. An even clay dispersion is a crucial property for a PCN, as it allows to best exploit the properties of the layered filler.

\begin{tabular}{|l|l|l|l|}
\hline \multicolumn{1}{|c|}{ Type of Clay } & \multicolumn{1}{c|}{ Ammonium cation } & \multicolumn{1}{c|}{ Type of blending } & \multicolumn{1}{c|}{ State of the rubber } \\
\hline pristine clay & $=$ & emulsion blending & in a latex \\
\hline pristine clay & added during blending & melt blending & in the melt state \\
\hline organoclay & in the organoclay & melt blending & in the melt state \\
\hline organoclay & in the organoclay & solution blending & in solution \\
\hline
\end{tabular}

Table 3. Processing methods of clays and organoclays with rubber

\subsection{Emulsion blending from a pristine clay}

Zhang first introduced the emulsion compounding: a mixture obtained from an aqueous clay suspension and a rubber latex was coagulated in an electrolite solution. This approach was applied for blending Mt in rubbers such as NR [28, 29], SBR [28-32], NBR [28, 29, 33], XNBR [29]. Moreover, bentonite was blended with SBR [34-37] and SVBR (V = vinylpiridine) [34, 35] and rectorite was blended in SBR [38, 39]. Different electrolytes were used: triethylenetetrammonium chloride (2\% wt solution) [29, 38, 39], diluted sulphuric acid solution [28, 30-32, 36], 1\% calcium chloride aqueous solution [32], dilute hydrochloric acid solution [34, 35, 37], dilute dichloroacetic acid solution [33]. A scheme for blending a pristine clay with a rubber latex, as reported by Zhang, is shown in Figure 4.

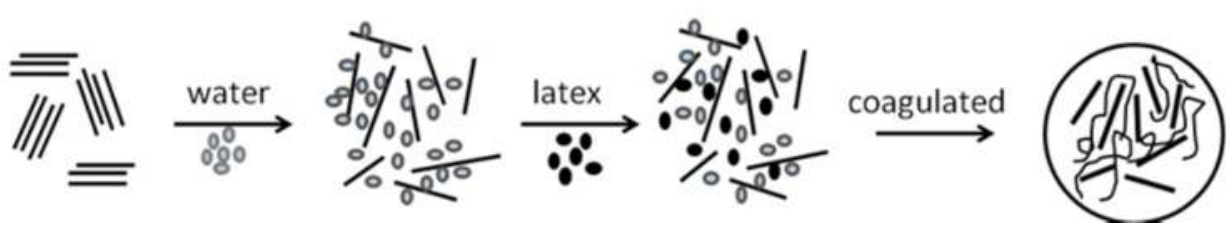

Figure 4. Emulsion blending of a pristine clay with a rubber latex

It was reported that the emulsion compounding led to nanocomposites, whereas conventional microcomposites were obtained when a pristine clay was melt blended with a rubber [28]. The Mt dispersion was commented to be excellent, up to $20 \mathrm{phr}$ as concentration, and best results were obtained with diluted sulphuric acid.

Modifications of this procedure, leading to satisfactory silicate dispersion, were adopted by:

i. adding a slurry containing further ingredients prior to coagulation, with NBR as the rubber and a sodium salt of methylene-bis-naphthalene sulphonic acid as the electrolyte. 
ii. adding further ingredients by melt mixing and avoiding the use of coagulating agents, with NR as the rubber [40]

iii. avoiding both coagulating agents and the addition of further ingredients, with NR as the rubber [41].

Bentonite and fluorohectorite (10 phr) dispersions in NR were observed to be to some extent worse when further ingredients were added prior to coagulation and coagulating agents were not used $[42,43]$.

When a prevulcanized NR latex was used, a minor amount of fluorohectorite layers and stacks with an increased distance between opposite layers were observed [44]. Fluorohectorite revealed a better swelling ability than bentonite and thus gave a more exfoliated structure [45].

\subsection{Melt blending from clays and organoclays}

Melt blending was performed with the help of the typical processing technologies of the rubber industry, from internal mixers such as brabender ${ }^{\circledR}$ and banbury ${ }^{\circledR}$ to open mills to twin screw extruders.

The melt blending of a pristine Mt with a rubber leads to composites with undispersed agglomerates, as demonstrated for NR [46-49], IR [50], BR [51-53], E-SBR [48, 54], ESBR/NBR blend [55], EPDM [56] as the rubbers. Analogous results were presented with fluorhectorite and attapulgite as the clays.

A satisfactory dispersion was achieved when the inorganic clays contained a lipophilic modifier [57]. With primary alkenylamines, exfoliated platelets and aggregates composed of different number of platelets were observed in the final composites, commenting that the $\mathrm{C}_{18}$ alkenyl group promoted a better dispersion with respect to the shorter ones.

An even dispersion of the organoclay in the rubber matrix was achieved in any the composites, though a fully exfoliated morphology was not achieved, when an ammonium cation with either three methyls and one long chain alkenyl substituent or two methyls and two long chain substituents was used. The polar hydroxyl group as ammonium cation substituent led to some layers agglomeration. These results were independent of the type of the rubber matrix.

\subsection{Solution blending from clays and organoclays}

Microcomposites were prepared when a bentonite or a Mt were mixed with the help of an organic solvent with many different types of rubbers: NR [58], BR [55], SBR [55, 59-61], (H)NBR [55, 62], BIMS [63]. Big lumps of clay aggregates and agglomerates were formed. Viceversa, an even dispersion of organoclays was achieved, when a clay containing a lipophilic ammonium as compensating cation was used. As reported in paragraph 4, different types of ammonium cations were used, in many types of rubber. A rationalization is proposed in ref. [57]. To summarize, the mentioned even dispersion was achieved in NR, 
$\mathrm{BR}, \mathrm{SBR}, \mathrm{NBR}, \mathrm{BIMS}$ and EPDM with a primary alkenyl amine as the clay modifier. In NR, IR, BR, SBR, (H)NBR when ammonium cations having either two or three methyl groups and longer chain substituents were adopted as clay compensating cations. Results appeared very similar to those obtained with melt blending.

\subsection{Formation of organoclays in situ in the rubber matrix}

The preparation of the organoclay in situ in the rubber matrix was reported by Galimberti [57, 64-67], by adopting the melt blending approach, with all the processing technologies mentioned in paragraph 5.2. An even clay dispersion was achieved in the rubber matrix and the organoclays revealed a lower number of stacked layers. This approach was adopted for many types of rubbers: IR, NR, SBR, NBR, XIIR, EPDM.

\section{Structure of RCN}

In this paragraph, the overall picture of RCN structure is presented, discussing in particular the interlayer distance of clays and the type of intercalants present in the interlayer space, of low molecular mass or polymeric.

This aspect is of the outmost importance for polymer clay nanocomposites. In fact, it is largely reported [1-22] that the intercalation of polymer chains in the interlayer space is at the origin of the remarkable properties of PCN. The intercalation of polymer chains is considered not only to favour the improvement of the polymer matrix but also to promote the clay exfoliation, leading to the ultimate clay dispersion. The overall picture of RCN, that is proposed for PCN is shown in Figure 5.

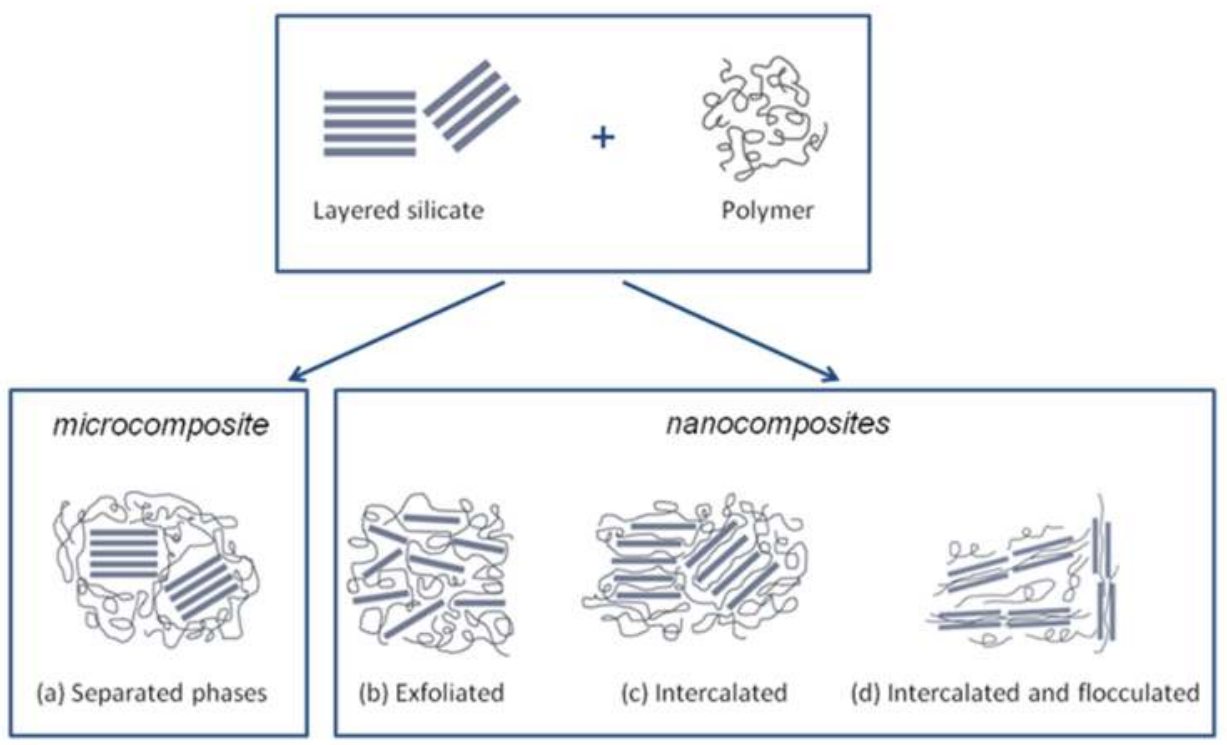

Figure 5. Overall picture of the structure of polymer (rubber) clay nanocomposites 
The study of the interlayer distance is performed through XRD and TEM analysis [57]. In particular, as discussed in paragraph 3, the modification of the interlayer distance, determined from XRD patterns, is taken as the evidence of the occurring of modifications in the interlayer space. It is worth summarizing here the two mechanisms proposed in the literature to explain the occurring of clay exfoliation and the modification of the interlayer distance.

\subsection{Two mechanisms for clays intercalation and exfoliation}

The two mechanisms can be visualized as reported in Figure 5 and are summarized as follows.
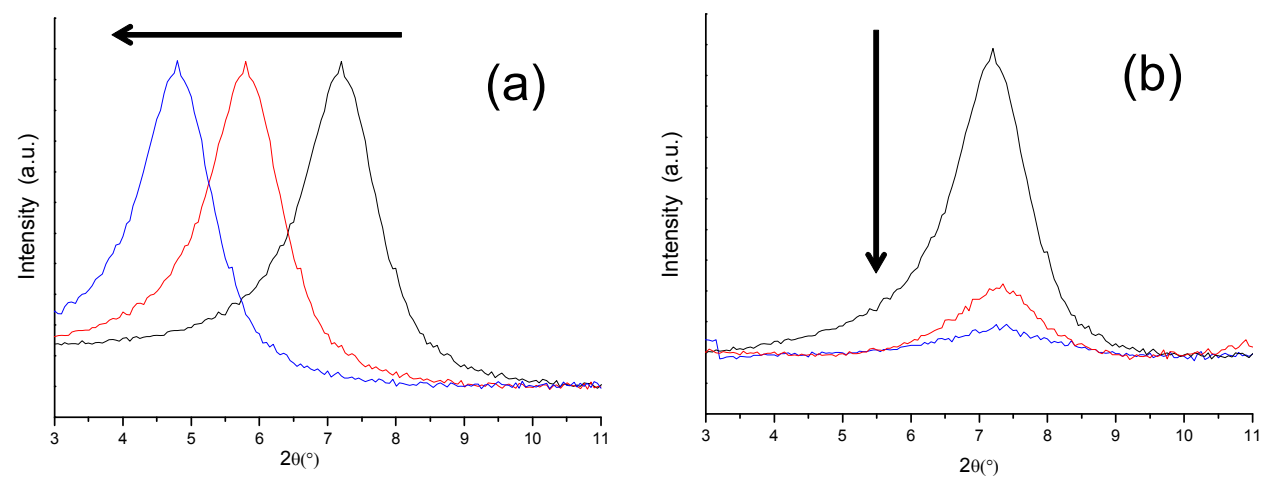

Figure 6. Schemes to visualize the two mechanisms proposed for clay intercalation and exfoliation: first mechanism (a), second mechanism (b) (see text for the explanation)

First mechanism. Polymer chains are intercalated in the interlayer space, with a consequent expansion of the interlayer distance. In Figure $6 a$, the position of the $(00 \ell)$ reflection progressively shift towards lower values of the $2 \theta$ angle, from black to red to blue curve, as a consequence of the progressive intercalation of the polymer chains. The intercalated polymer chains are not only responsible for the expansion of the interlayer distance but also cause the separation of clay layers, promoting the ultimate exfoliation. This first mechanism, originally proposed for polystyrene as the polymer, is widely accepted in the prior art.

Second mechanism. The intercalation of polymer chains is regarded as unlikely and only low molecular mass substances are considered to be present in the interlayer space, when crystalline OC are formed. In particular, it is commented that it is hard to suppose that highly crystalline structures (as shown by the presence of several $(00 \ell)$ reflections in the XRD pattern), can be generated in the presence of a polymer chain. The variation of the interlayer distance is seen as a consequence of: (i) the different arrangements of the substituents of the compensating cations, that indeed can give rise to different doo1 values (as shown in Table 2) and/or (ii) of intercalation of guests in the interlayer space and/or (iii) of molecules absorption on clay surfaces. The clay exfoliation occurs through a progressive peeling off of the clay stacks thanks to the shear mixing. In Figure $6 \mathrm{~b}$, the $(00 \ell)$ reflection 
remains at the same $2 \theta$ value and its intensity decreases, passing from the black to the red to the black curve, as a consequence of the progressive exfoliation of the clay stacks. Authors presenting this mechanism propose the scheme reported in Figure 7, where the XRD pattern of nanocomposites in the low $2 \theta$ region (peaks are due to $(00 \ell)$ reflections are shown as well the mechanism hypothesized for their formation.

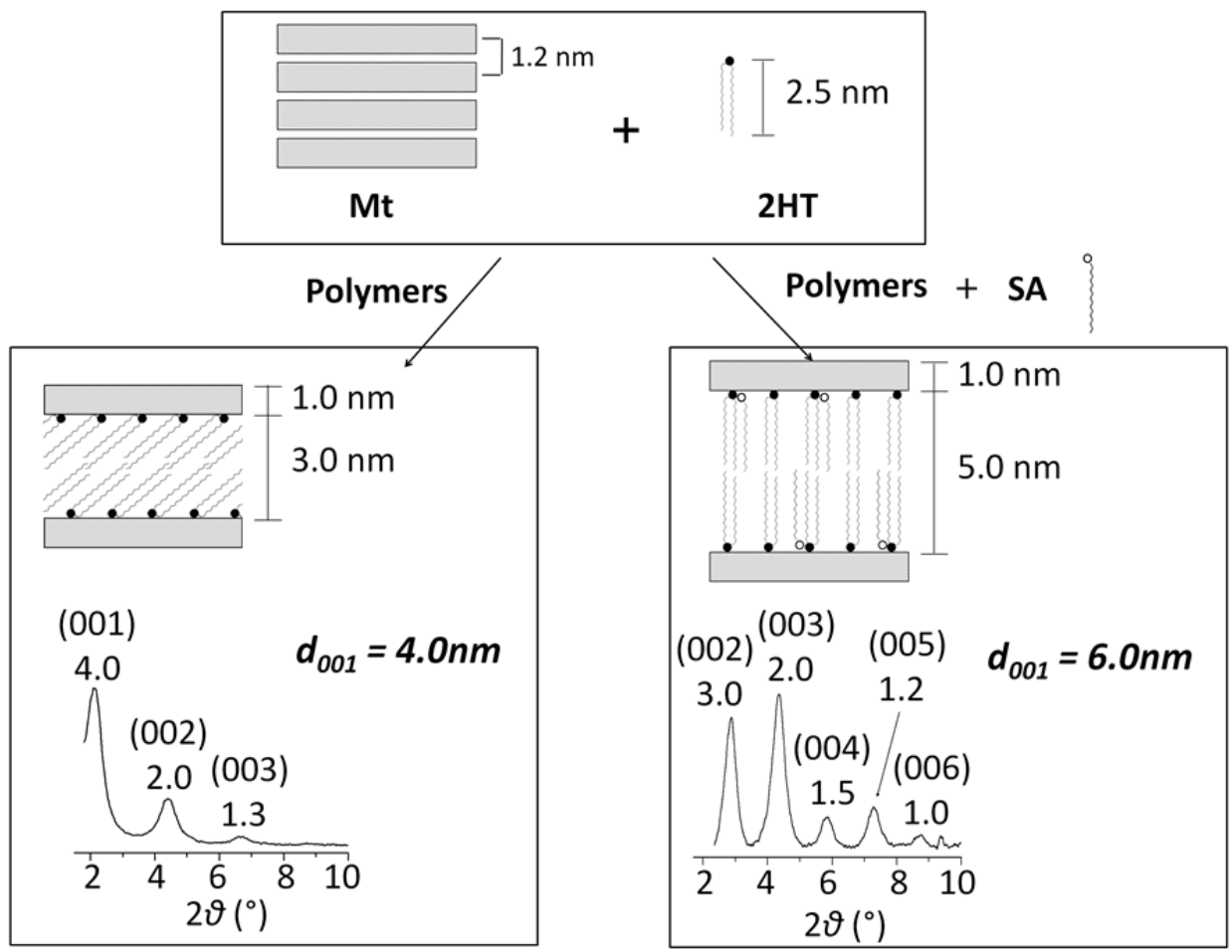

Figure 7. Schematic presentation for the formation of an organoclay by blending Na-Mt with di(hydrogenated tallow)-dimethylammonium chloride (2HT), in the absence or in the presence of stearic acid (SA) (Scheme reproduced from ref. 66)

\section{Rheology of RCN}

Clays compatibilized and evenly dispersed in a polymer matrix tend to build networks at low concentration. Rheological measurements, performed on RCN based on various types of rubbers, revealed the pronounced rubber-clay interaction, when measurements were taken at zero shear. The storage modulus in the low frequency region was investigated as a function of clay content and the clay percolation threshold (as $w \mathrm{t} \%$ ) was found to be about 4 (OC was $\mathrm{Mt} /$ methyl tallow bis-2-hydroxyethyl ammonium cation), above 5 (OC was $\mathrm{Mt} /$ dimethyl-dialkylammonium halide $(70 \% \mathrm{C} 18,26 \% \mathrm{C} 16$ and $4 \% \mathrm{C} 14)$ ) and above 7.5 (OC was $\mathrm{Mt}$ / dimethyl dehydrogenated tallow quaternary ammonium chloride) for IR, EPR and EVA, respectively [68-71]. The filler networking phenomenon was observed as well in 
matrices based on IR, ENR [72], SBR [73] and EPR [69]. At zero shear, the viscosity of RCN is thus higher than the one of the neat elastomer.

However, organophilic clays were shown to reduce the steady shear viscosity of RCN. Most evident results were a pronounced shear-thinning behaviour, increasing with the clay content, a higher extent of extrudate, a lower swelling and a better surface smoothness, by increasing the shear rate. These findings are of great importance, as they indicate that OC have a positive effect on the processability of rubber compounds. Data were reported for RCN based on various rubbers, such as BR [60], SBR [60], NBR [60], BIMS [74] and fluoroelastomer [75]. A compensating cation with longer alkyl chains led to a reduction of Mooney viscosity, that was not observed with a short chain substituent [76].

This behaviour of OC, that is opposite to that of traditional fillers, is attributed to the orientation, occurring at high shear rates, of clay platelets along flow direction, and to the slippage of platelets on the chains, thanks to the organophilic clay substituents. Data to demonstrate that were provided with an OC (Mt/octadecyltrimethylammonium) in BR [77] and with another OC (Mt/dimethyl hydrogenated-tallow (2-ethylhexyl) quaternary ammonium methylsulfate) in poly(epichlorohydrine) [78].

The improvement of processability brought about by OC was found to be higher when the matrix was apolar rubber such as NBR [79].

\section{Vulcanization of RCN}

OC promote a fast sulphur based crosslinking of unsaturated polymer chains. Moreover, they increase the delta torque value indicating a higher value of crosslinking density [80].

Many data were reported in the literature, supporting these conclusions, in rubbers such as NR (hexadecyltrimethyl ammonium, octadecyltrimethyl ammonium, tetraoctyl phosphonium, triphenyl vinylbenzyl phosphonium, octadecylamine chloridrate were used as intercalants) [81-86], SBR (Mt/octadecyltrimethylamonium) [87], (NBR (octylamine; dodecylamine and octadecylamine chloridrates were the intercalants) [76]. A reduction of the activation energy for sulphur based NR crosslinking was found by using a bentonite modified with octadecylamine chloridrate $[83,88]$. OC could thus present a warning, as they could lead to premature scorching but, at the same time, they could present the chance of performing vulcanization reactions at lower temperatures.

To explain the behaviour of OC in sulphur based crosslinking, the formation of tertiary amines from the thermal degradation of ammonium cations and the enhanced mobility of sulphur accelerating anionic species were proposed [89].

\section{Barrier properties of $\mathrm{RCN}$}

The reduction of air permeability thanks to clays dispersed in a poly(isobutene) matrix led to the first commercial application of RCN, that will be discussed in Paragraph 11.2. 


\subsection{The tortuous path model}

Platelets with a high aspect ratio substantially reduce the diffusion of penetrating molecules in polymer matrices. The tortuous path model, represented in Figure 8, is generally accepted to explain this result.

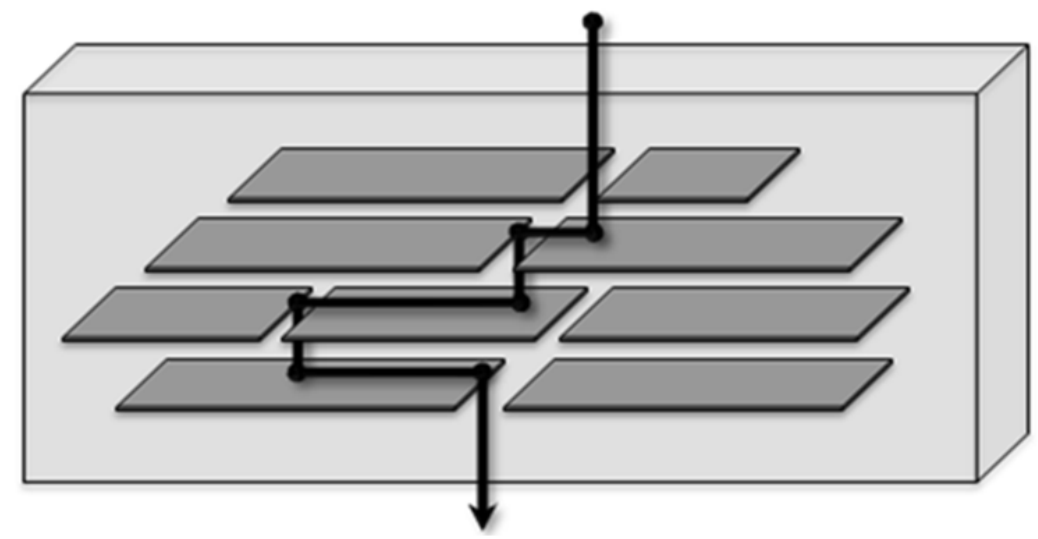

Figure 8. Tortuous path for molecules in a matrix containing platelets

Various continuum models were developed and applied to polymer clay nanocomposites, assuming in most cases a random dispersion of plates, parallel to each other and perpendicular to the direction of molecules diffusion, as summarized in refs. [90] and [91]. According to these models, reduction of permeability is enhanced by the increase of the platelet aspect ratio. These models are able to interpret the reduction of permeability in a polymer matrix, without necessarily having the presence of nano-platelets. This means that a nano-effect should not be invoked. It was commented [91] that permeating molecules have a sub-nano level and their permeation is slowed down by platelets, whatever is their size.

\subsection{Improvement of barrier properties of rubber matrices thanks to the use of clays}

Better barrier properties of a rubber matrix, thanks to clay addition, were demonstrated for many different rubbers. In NR as the matrix, the barrier properties were enhanced at low clay $(\mathrm{Mt})$ content, preparing the nanocomposite through the emulsion blending: 1,2 and 3 phr of clay led respectively to more than $35 \%$ and to about $45 \%$ and $50 \%$ reduction of oxygen permeability [92]. $3 \mathrm{phr}$ of OC (Mt/ didodecyl methyl amine) gave a $50 \%$ reduction of the oxygen permeability and a $40 \%$ reduction of toluene absorption at 20 ${ }^{\circ} \mathrm{C}$ [93]. 5 and 10 phr of OC led, respectively, to about $10 \%$ and $15 \%$ reduction of the oxygen permeability, and, at $15 \%$ OC, to a $30 \%$ reduction of toluene absorption at $30^{\circ} \mathrm{C}$ [94]. In BR as the matrix, 5 phr OC (Mt/dimethyl ditallow-ammonium) dispersed from solution blending, led to a reduction of about $80 \%$ of water vapour permeability, whereas $10 \mathrm{phr}$ OC gave about $20 \%$ reduction of toluene uptake at equilibrium [95]. In NBR as the 
matrix, 1 phr of OC (Mt/dimethyl ditallow-ammonium) dispersed from solution blending brought to about $80 \%$ decrease of water vapour permeability [96]. Better barrier properties were observed by increasing the AN content of NBR: the relative nitrogen permeability was reduced by $11.5,10.4$, and $9.0 \%$ for $42 \mathrm{NBR}, 35 \mathrm{NBR}$, and $26 \mathrm{NBR}$ (the figures indicate the $\mathrm{wt} \%$ of $\mathrm{AN})$, respectively, with $10 \mathrm{phr}$ OC (Mt/dimethyl dialkyl (C14C18) ammonium) [97].

A clay with a high aspect ratio such as rectorite was found to give better barrier than carbon black N330 [38].

\section{Mechanical properties of RCN}

\subsection{The origin of reinforcement: nano-structured and nano-fillers}

Particulate fillers are used to reinforce traditional rubber compounds: they are carbon black and silica and are made by spherical individual particles of few tents of nanometers as the diameter, fused together to form aggregates extending up to few hundreds of nanometers. These fillers are called nano-structured as the aggregates can not be separated into individual particles by thermomechanical mixing.

Theories on the origin of reinforcement [98], developed on carbon black based compounds, led to present the modulus of a filled rubber compound as due to the sum of different contributions, as it shown in Figure 8.

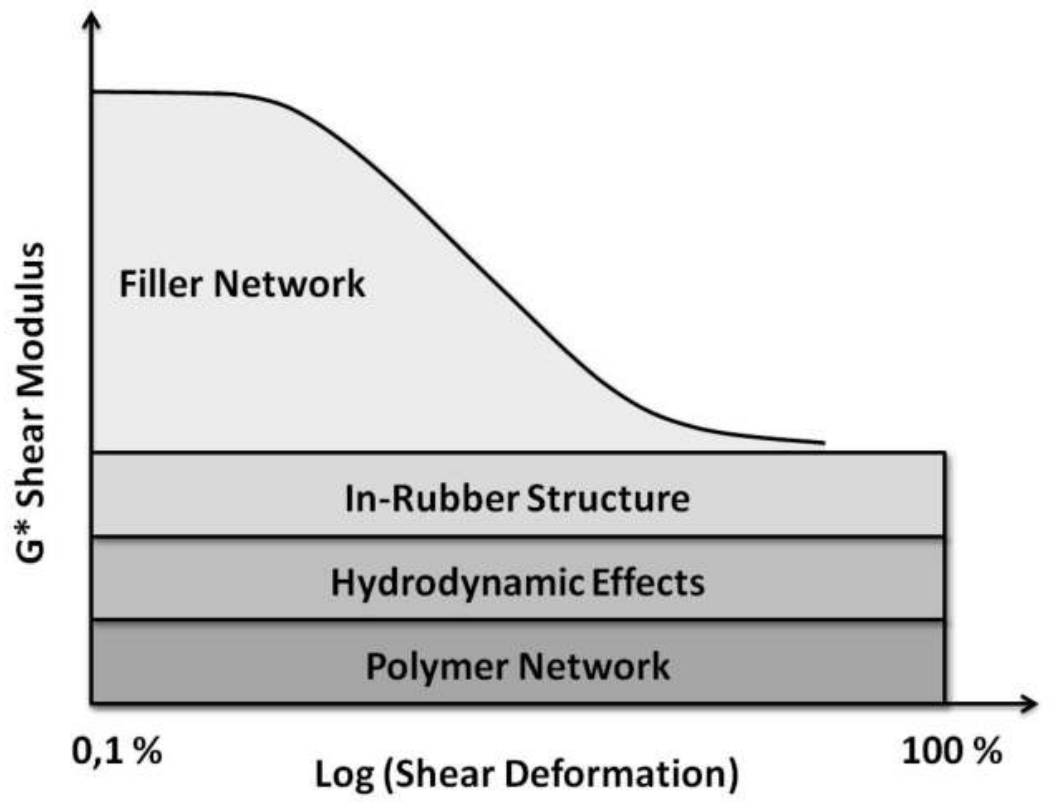

Figure 9. Contributions to the modulus of a rubber compound filled with a particulate filler 
Contributions that do not depend on the strain amplitude are due to the polymer network (entanglements, physical and chemical crosslinks), hydrodynamic effects (related to the filler volume fraction and implying the strain amplification mechanism and thus the enhancement of the modulus), immobilization of rubber on filler particles (that transform a highly viscous liquid in a solid). A contribution to the modulus that strongly depends on the strain amplitude is due to the so called filler network: filler particles are joined together either directly or through polymer layers.

The Guth Equation is used to correlate the compound initial modulus with the filler volume fraction (equation 1 as follows).

$$
E=E m\left(1+0.67 \mathrm{f} \phi+1.62 \mathrm{f}^{2} \phi^{2}\right)
$$

This equation holds up to a threshold of filler content, known as the percolation threshold, at which a continuous network is established in the rubber matrix and thus accounts for the sum of the three contributions commented above and shown in Figure 8 that do not depend on the strain amplitude.

In equation 1, appears the shape factor $f$, that was already commented in Paragraph 2. The shape factor $f$ was introduced in the Guth model in order to account for the fact that particle aggregation (clustering) has a significant impact on stiffness at high volume fractions (higher than 0.15). These clusters are formed by the filler aggregates and the impact of the $f$ value on the quadratic term of the Guth equation makes them much important for the total value of the modulus.

In the case of a clay, as it was shown in Figure $1 \mathrm{~b}$, the shape factor $f$ is given by the ratio between the longest lateral side of the layer and the height of clay stacks, the highest $f$ value being obtained in the case of a single layer. Therefore, the exfoliation of a clay not only favours a better clay dispersion but also improves the modulus of the compound. To take into account the lower contribution to the modulus of a platelet like filler, a modulus reduction factor of about 0.7 was determined [99] by fitting experimental data.

An important contribution to the reinforcement is given by the so called "in rubber structure": fillers are able to accomodate polymer chains in the voids of their structure. This mechanism is well known in the case of nanostructured fillers such as carbon black and silica. In the case of clays, the immobilization of polymer chains would require their intercalation in the interlayer space, phenomenon that is however, as explained in paragraph 6.1, still a matter of debate.

OC give an important contribution to the polymer network. In fact, as discussed in paragraph 8, they promote a higher crosslinking density, thanks to the cation-thiolate interaction. Clay layers and aggregates could be represented as framed in a cage formed by short sulphur bonds, that prevents their slip on the polymer chains, phenomenon that occurs in uncrosslinked samples, as commented in paragraph 7.

In the same paragraph, it was commented that a low clay concentration is needed for achieving the percolation threshold in a hydrocarbon rubber matrix. This conclusion was 
drawn also by determining the dependence of the Young modulus (obtained from stress-strain curves) on the OC concentration, in a SBR matrix (with Nanomer I.42E from Nanocor as OC) [100] or in an isoprene rubber matrix (OC was $\mathrm{Mt} / 2 \mathrm{HT}$ ), either synthetic [67] or naturally occurring [101]. The excess of the Young modulus was plotted versus the filler fraction [102], determining the percolation threshold, that was: $2.7 \mathrm{vol} \%$ in SBR [100], $2.9 \mathrm{vol} \%$ in IR [67] and 4 vol \% in NR [101]. The excess modulus scales with a power law with an exponent between 1.8 and 2.5 above the percolation threshold, lower with respect to the one typical of carbon black (about 4). The structural difference of the filler is proposed to justify this difference. As mentioned above, the filler network is responsible for the contribution to the modulus that depends on the strain amplitude. Thanks to the easy formation of a filler network, clays promote a remarkable non linearity of the dynamicmechanical behaviour of rubber nanocomposites, a phenomenon known as Payne effect [103]. Data that the show the remarkable Payne effect of RCN, increasing with the clay content, were reported for NR [104] and IR [67] as the rubber matrices. A strong reduction of the dynamic modulus was observed also by increasing the temperature [50]. The 2-D melting of the paraffinic chains substituents of the compensating ion [105] was commented as a possible explanation $[66,101]$.

\subsection{The improvement of rubber mechanical properties thanks to the use of clays}

Many data are available in the literature to show that both pristine clays and OC bring about the improvement of the mechanical properties of a rubber matrix, preparing the nanocomposites from latex, melt and solution blending. Some examples are reported as follows.

Pristine Mt was dispersed in a NR latex, observing an increase of modulus for the obtained nanocomposite up to $30 \mathrm{phr}$ of clay, in the presence of worse ultimate properties [41], as well as higher $300 \%$ stress, shore A hardness, tensile strength and tear strength, when $\mathrm{Mt}$ was at $20 \mathrm{phr}$ level [29]. In a SBR matrix as well, tensile and tear strengths were improved by adding a pristine Mt via emulsion blending, up to 20 phr [29], without any improvement for a further addition [35].

OC were typically used at lower levels. In NR as the matrix, $5 \mathrm{phr}$ of Mt modified by tetraoctyl phosphonium bromide led to a 3-fold increase of tensile strength [81] and best ultimate properties were obtained with $10 \mathrm{phr}$ of OC (Mt/octadecyltrimethyl ammonium) [106]. In BR as the matrix, best mechanical properties were obtained with a Mt having dimethyl dihydrogenated tallow quaternary ammonium as the compensating cation [107], an ammonium cation largely diffused in RCN field. In a SBR matrix, mechanical properties improved up to $10 \mathrm{phr}$ of OC (Mt/octadecyltrimethylamine, Nanomer I.28E) [87] (Mousa and Karger-Kocsis, 2001), decreasing for a further addition. In a nanocomposite based on maleic anhydride modified EPM (EPM-MA, with $0.42 \mathrm{wt} \%$ of maleic anhydride) about $5 \%$ of OC (Mt/octadecyl amine) gave a modulus three times higher than that of EPM-MA. Modulus increased and elongation at break decreased with clay content [108]. 
Reinforcement was obtained from $O C$ also in rubber blends. 2 phr of $O C$ (Mt/octadecyltrimethylamine) in an NR/ENR blend (10 phr ENR50) gave an increase of both strain and stress at break values [109] (Teh et al., 2004).

It was commented in Paragraph 7 the importance of sulphur based vulcanization to prevent the OC slip on the polymer chains. OC (Mt modified with hydrogenated tallow ammonium) was reported to promote a remarkable reinforcement also of a peroxide cured rubber matrix. However, in this case, the rubber was NBR, with acrylonitrile content as high as $50 \%$ [110]. It was also shown that higher values of tensile strength and better tear resistance were obtained, with a worse elongation at break, by increasing the AN content, with 10 phr of OC (Mt/dimethyl dialkyl (C14-C18) ammonium) [111].

\subsection{Clays in a rubber matrix for lighter weight of the compound}

The most important application of rubber compounds is in tires. Lighter rubber compounds are thus pursued, in the light of their remarkable impact on the environment. Direct comparisons were reported between $\mathrm{OC}$ and $\mathrm{CB}$ in promoting the mechanical reinforcement of rubber compounds.

In NR as the matrix, a comparable mechanical reinforcement was obtained with $10 \mathrm{phr}$ OC (Mt/octadecylamine) and $40 \mathrm{phr} \mathrm{CB}$, with almost twice elongation at break, a lower compression set and similar abrasion loss with OC [112]. With the same OC, a much lower heat build up was obtained with respect to $50 \mathrm{phr}$ of CB [113].

In $\mathrm{BR}$ as the matrix, better mechanical performance was obtained with $3 \mathrm{phr}$ OC (Mt/dimethyl dihydrogenated tallow quaternary ammonium) compared with $10 \mathrm{phr}$ of $\mathrm{CB}$ [114]. In NBR as the matrix, a comparable tensile strength was obtained with either $10 \mathrm{phr}$ OC or with 40 phr CB [115]. In EPM-MA, 5\% of OC (Mt/octadecyl amine) gave the same reinforcement as $30 \mathrm{wt} \% \mathrm{CB}$ [108].

\subsection{Synergistics effects between clays and nanostructured fillers}

An increasing number of studies is becoming available in the literature on RCN based on clays and a nanostructured filler such as silica and, in particular, CB. A large scale application of RCN could reasonably imply the use of hybrid filler systems, with a minor amount of OC added to a major part of a traditional filler. In SBR as the matrix, a hybrid sepiolite-silica filler system was adopted [116]. Hybrid OC/CB filler systems were used in the following matrices: SBR [117-119], brominated poly(isobutylene-co-paramethylstyrene) rubber [117], IR [50, 57, 120], NR [67, 121] NR/SBR blend [122], chlorobutyl rubber [123], ENR [124], EPDM [125] (Malas and Das, 2012). In some of these works [50, 57, 120-122], CB was used at a level typical of commercial applications (higher than $50 \mathrm{phr}$ ). A remarkable enhancement of material dynamic-mechanical properties was reported, thanks to the use of the hybrid filler system. The most important finding from these study was the synergism developed by the two fillers [118, 120, 121]. In particular, it was shown [126] that initial modulus values obtained with the hybrid CB-OMt filler system were much higher than 
those calculated through the simple addition of the two initial moduli of composites with only CB or only OC. Figure 9, taken from ref. [127], demonstrates the synergistic effect between $\mathrm{OC}$ and $\mathrm{CB}$. The dashed line indicates the initial modulus calculated by simply adding the initial moduli of composites with only $\mathrm{CB}$ and only $\mathrm{OC}$, whereas points refer to experimental data taken from composites containing the hybrid filler system.

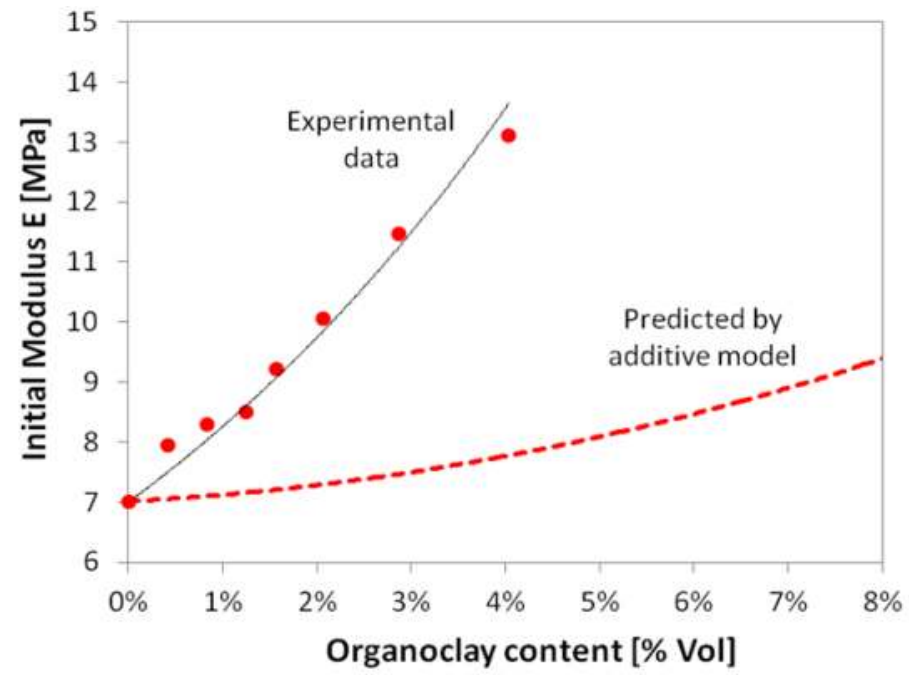

Figure 10. Initial modulus values $(\bullet)$ of IR based composites containing the hybrid OC/CB filler system. The dashed line refers to values predicted through the addition of initial moduli values of composites with only CB and only OC.

\section{Applications of RCN}

In this paragraph, applications of RCN are examined, moving from products already available on the commercial scale. The most meaningful patents were taken as the reference literature for the considered applications. RCN applications, diffused on the commercial scale, well documented and advertised, are essentially in two fields: tires and sport balls.

\subsection{Applications of RCN for tyres}

The most abundant application for rubbers is in tire compounds. NR is the most diffused rubber, with almost 11 million ton in 2010 [128] and SBR is the most produced synthetic rubber, with about 6 million ton. The application of both these rubbers is for about $75 \%$ in tire compounds. The world demand for tires is rising, at a pace of about 4.7 per year through 2015 , achieving a number of produced tires of about 3.3 billion units. In the same period, the tire market is projected to increase, in terms of value, of about 6.5 percent annually, achieving a total value level of $\$ 220$ billion 129]. It is thus evident that the application of $\mathrm{RCN}$ in tire compounds can lead to a real commercial diffusion as well as to an important economic impact. 
A tire can be defined as a toroidal high performance composite behaving as a flexible membrane, able to contain gases under pressure and with the following capabilities: load carrying, cushioning, road handling. Figure 9 reports the structure of a tire, with the name of constitutive parts.

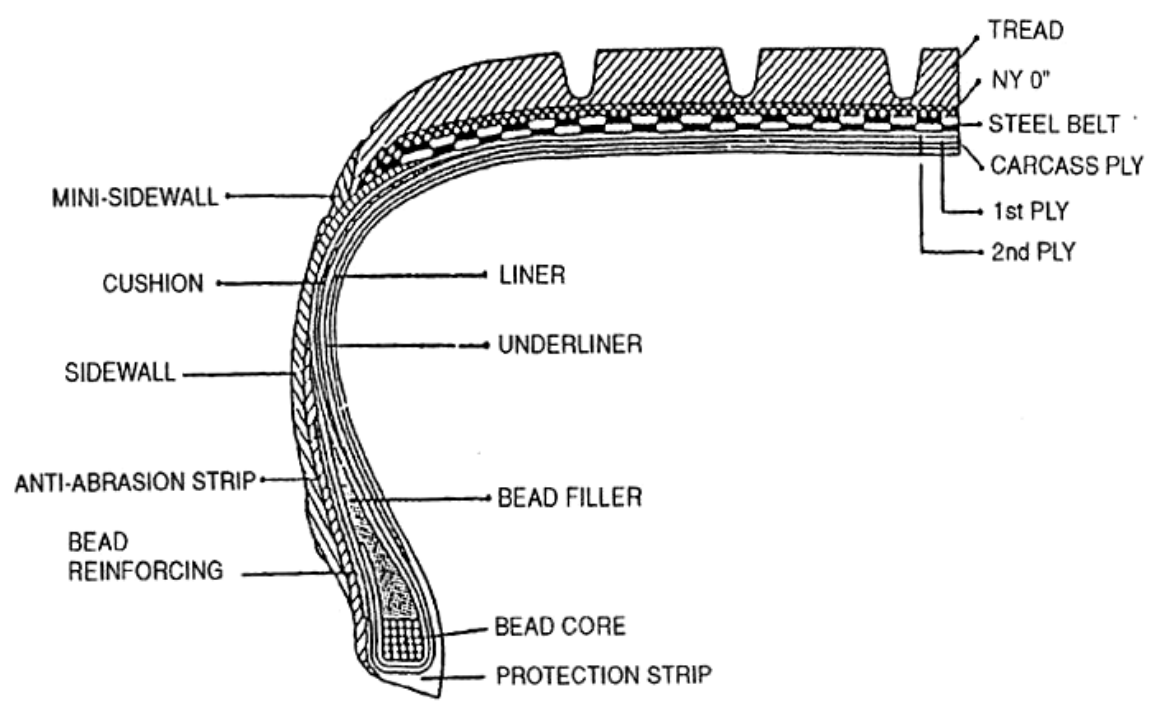

Figure 11. Structure of a tire

RCN have been so far essentially applied in three parts of a tire: tread, base (i.e. a compound immediately before the tread in contact with the road), liner. Table 4 explains the position in a tire of such compounds and clarifies their role.

$\mathrm{RCN}$ in tire compounds are used to achieve the following properties and performances: reduced weight, reduced energy dissipation, enhanced air retention and extension of the balance of the so called magic triangle performances for a tire tread: rolling resistance, traction, wear.

RCN in tire treads. By examining the patent literature [130-132], it appears that clays were used in tire tread compounds aiming at longer life of the compound and lower fuel consumption without negatively affecting the tread grip on the road at low temperature. Clays were used with or without an ammonium cation modifier, in the former case in the presence of a large amount of silica. Compound properties claimed in patents are: better ultimate properties, lower abrasion and an hysteresis that remains analogous at low temperature and is lower at medium - high temperature.

RCN in base compounds. OC were used in base compounds of tires commonly referred to as "HP" (High Performance) or "UHP" (Ultra high performance) tires, belonging to classes "V" or " $\mathrm{Z}$ ", designed to experience extreme driving conditions, as they achieve maximum speeds in a range from 210 to $240 \mathrm{~km} / \mathrm{h}$ and higher than $240 \mathrm{~km} / \mathrm{h}$, respectively. In this type 
of tires, a low thickness base compound is used to favour performances such as tread block stability, road grip, steering stability, cornering stability and ride comfort. This base compound should have high tensile and dynamic-mechanical properties. OC were reported in the patent literature to give a remarkable improvement of the compound dynamic mechanical properties [133-136] and Pirelli Tire launched in 2007 P Zero tires for the HP and UHP segments, with a base compound containing an OC. In particular, it was reported that OC was able to give a much more isotropic behavior (i.e. an equal performances in longitudinal and lateral directions), with respect to traditional reinforcing fibers, such as the aramide ones.

\begin{tabular}{|l|l|l|}
\hline Tyre compound & Position in the tyre & Performances \\
\hline Tread & In contact with road & $\begin{array}{l}\text { Dry, wet, ice and snow traction. } \\
\text { Stability at high speed. Abrasion } \\
\text { resistance. Protection of } \\
\text { compounds below. }\end{array}$ \\
\hline Base (tread cushion) & $\begin{array}{l}\text { Below the tread. } \\
\text { Between tread and nylon } 0^{\circ}\end{array}$ & $\begin{array}{l}\text { Low hysteresis. Good adhesion. } \\
\text { Good fatigue, tear and } \\
\text { durability. Compatibility }\end{array}$ \\
\hline $\begin{array}{l}\text { Liner or innerliner } \\
\text { of impermeable rubber. }\end{array}$ & Under the carcass & $\begin{array}{l}\text { Impermeability to air and } \\
\text { moisture. Prevention of } \\
\text { degradation of tire structure } \\
\text { (due to air and moisture). } \\
\text { Good flex fatigue, crack, long } \\
\text { term aging resistance. }\end{array}$ \\
\hline
\end{tabular}

Table 4. Tyre compounds explored for RCN application

RCN in innerliner. Most research efforts were dedicated to develop OC based innerliner compounds, with the aim to exploit the barrier property provided by clay platelets, trying in particular to achieve a high clay dispersion. In order to have the best barrier, the following technical solutions were adopted: use of clays with a high aspect ratio, control of the clay organization (stacks of exfoliated layers), use of reactive rubbers to promote the clay exfoliation, use of coating layers with a high impermeability.

A kaolin [137] and a mica [138] with high aspect ratio (at least 50) were used in butyl and in butyl, butadiene and natural rubber, respectively.

Stacks of OC were used in BR [139], in BIMS [140] and in SBR [141]. With an OC content as low as $9 \mathrm{phr}$, the oxygen transmission was reduced to about one fourth [139].

The clay exfoliation was promoted either by dispersing clays in the emulsion were polymerization of monomers such as isoprene and styrene was performed [142], or by performing the exchange reaction with a cationic polymer latex [143], or by mixing the clay (in a BIMS matrix) in the presence of a tertiary amine. In this latter case, with only $3 \mathrm{phr}$ of clay, a reduction of $20 \%$ permeability was detected [144]. 
An amine terminated oligomer (e.g. a butadiene-acrylonitrile copolymer) was used as the reactive polymer to prepare a 25/75 clay/SBR blend and the oxygen transmission was reduced to less than one half [145]. A clay was mixed with a aqueous dispersion of a dienebased elastomer, with one or more functional groups such as acid or an anhydride [146].

OC was melt blended with poly(isobutylene-co-p-alkylstyrene) and poly(isobutylene-coisoprene) elastomers and at a concentration of $10 \mathrm{phr}$ the permeability was reduced to one half [147]. OC was melt blended with an halogenated copolymer of isobutylene and pmethyl-styrene and, at an OC level of $5 \mathrm{phr}$, the air retention was improved up to 30\% [148]. Poly(isobutylene-co-N,N-dimethylvinylbenzylamine) copolymer was blended with an OC and an improvement of impermeability up to $70 \%$ was reported [149].

Barrier coating mixtures were prepared by mixing an elastomer (butyl rubber) an exfoliated clay with a high aspect ratio (preferably a vermiculite) and a surfactant, adopting a polymer/clay ratio from 1:1 to 20:1 and obtaining a permeability reduction of about $25 \%$. This technology found a large commercial success in tennis ball and it will be discussed in the following paragraph [150].

\subsection{Applications of RCN for sport balls}

As mentioned above, a clay based barrier coating technology was developed [151-154], and applied to sport balls, with the aim to drastically improve the pressure retention without negatively affecting properties such as the bounce, the feel and the reproducibility of performances. A relatively thin coating layer (about 10-30 micron) was deposed, made by an elastomeric nanocomposite prepared by combining aqueous dispersions of a vermiculite (having a aspect ratio up to 1000) and butyl rubber. In a laboratory study [90] (Takahashi et al., 2006) a coating layer containing vermiculite (20 - $30 \mathrm{wt} \%)$ in butyl rubber led to a reduction of the diffusion coefficients by two orders of magnitude and of gas permeability by 20-30 fold. This technology was developed by InMat company and Air D-Fense products were commercialized.

\section{Author details}

Maurizio Galimberti

Politecnico di Milano, Dipartimento di Chimica,

Materiali e Ingegneria Chimica G. Natta, Milano, Italia

\section{References}

[1] Giannelis E.P., Krishnamoorti R., Manias E. (1999) Polymer-Silicate Nanocomposites: Model Systems for Confined Polymers and Polymer Brushes. Adv. Polym. Sci. 138: 107147.

[2] Alexandre M., Dubois P. (2000) Polymer-layered silicate nanocomposites: preparation, properties and uses of a new class of materials. Materials Science and Engineering. 28: $1-63$. 
[3] Ray S.S., Okamoto M. (2003) Polymer/layered silicate nanocomposites: a review from preparation to processing. Progr. Polym. Sci. 28: 1539 - 1641.

[4] Gao F. (2004) Clay/polymer composites: the story. Materials Today 7(11): 50-55.

[5] Utracki L.A. (2004) Clay-Containing Polymeric Nanocomposites. Rapra Technology Ltd, Shawbury, Shrewsbury, Shropshire UK

[6] Ray S.S., Bousmina M. (2005). Biodegradable polymers and their layered silicate nanocomposites: In greening the 21st century materials world. Progress in Materials Science. 50: 962-1079

[7] Okada A., Usuki A. (2006). Twenty Years of Polymer-Clay Nanocomposites. Macromol. Mater. Eng. 291: 1449-1476

[8] Kotsilkova R. (2007) Thermoset nanocomposites for engineering applications. Ismithers Rapra Publishing, UK, 344.

[9] Utracki L.A., Sepehr M., Boccaleri E. (2007) Synthetic, layered nanoparticles for polymeric nanocomposites (PNCs), Polym. Adv. Technol., 18: 1-37.

[10] Chen B., Evans J.R.G., Greenwell H.C., Boulet P., Coveney P.V., Bowden A.A., Whiting A. (2008) Chem. Soc. Rev. 37: 568-594.

[11] Garces J.M., Moll D.J., Bicerano J., Fibiger R., McLeod D. G. (2000) Polymeric Nanocomposites for Automotive Applications. Adv. Mater., 12:1835-39

[12] Mittal V. (2010) Advances in Polyolefin Nanocomposites. CRC Press Taylor and Francis Group, London (UK).

[13] Kato M., Usuki A., Hasegawa N., Okamoto H., Kawasumi M. (2011) Development and applications of polyolefin- and rubber-clay nanocomposites. Polymer Journal 43: 583593.

[14] Karger-Kocsis J., Wu C.M. (2004) Thermoset Rubber/Layered Silicate Nanocomposites. Status and Future Trends. Polym. Eng. Sci. 44: 1083-1093.

[15] Varghese J., Karger-Kocsis, J. (2004) Rubber World 4: 32-38.

[16] Bandyopadhyay A., Maiti M., Bhowmick A. K. (2006) Synthesis, characterisation and properties of clay and silica based rubber nanocomposites, Mater. Sci. Technol., 22(7): 818-828.

[17] Sengupta R., Chakraborty S., Bandyopadhyay S., Dasgupta S., Mukhopadhyay R., Auddy K., Deuri A.S. (2007) A Short Review on Rubber/Clay Nanocomposites With Emphasis on Mechanical Properties, Polym. Eng. Sci., 47(11): 1956-1974.

[18] Maiti M., Bhattacharya M., Bhowmick A.K. (2008) Elastomer Nanocomposites, Rubber Chemistry and Technology 81: 384-469.

[19] Sabu T., Ranimol S., (Eds.) (2010) Rubber Nanocomposites. Preparation, Properties and Applications. Wiley and Sons, New York. 705.

[20] Galimberti M. (2011) Rubber Clay Nanocomposites-Science, Technology and Applications, Wiley and Sons, New York.

[21] Mittal V., Kim J.J., Pal K., (Eds.) (2011) Recent Advances in Elastomeric Nanocomposites, Springer-Heidelberg Dordrecht London New York

[22] Bergaya F., Jaber M., Lambert J.-F. (2011) Clays and Clay Minerals. In: Galimberti M. (Ed.), Rubber Clay Nanocomposites - Science, Technology and Applications, Wiley and Sons, New York, Chapter 1: 3-44. 
[23] http://www.bsi-global.com/en/Standards-and-Publications/Industry-Sectors/ Nano technologies/ PAS-71/Download-PAS-712005-Vocabulary-Nanoparticles

[24] Bergaya F., Jaber M., Lambert J.F. (2011) Organophilic Clay Minerals. In: Galimberti M. (Ed.), Rubber Clay Nanocomposites - Science, Technology and Applications, Wiley and Sons, New York, Chapter 2: 45-86.

[25] SCENIHR (Scientific Committee on Emerging and Newly-Identified Health Risks) 21-22 June 2007.

http: //ec.europa.eu/health/ph_risk/committees/04_scenihr/docs/scenihr_o_010.pdf

[26] Klug H.P., Alexander L.E. (1959) in X-ray diffraction procedure Wiley NY. Chapter.3 Fundamental Principles of X-ray Diffraction pp.120-174

[27] Klug H.P., Alexander L.E. (1959) in X-ray diffraction procedure Wiley NY, Chapter 9

[28] Wu Y., Huang H., Zhao W., Zhang H., Wang Y., Zhang L. (2008) Flame retardance of MMT/rubber composites. Journal of Applied Polymer Science. 107: 3318-3324

[29] Wu Y., Wang Y., Zhang H., Wang Y., Yu D., Zhang L., Yang J. (2005) Rubber-pristine clay nanocomposites prepared by co-coagulating rubber latex and clay aqueous suspension, Compos. Sci. Technol. 65: 1195-1202

[30] Ray S.; Bhowmick A. K.; Sarma K. S. S.; Majali A. B.; Tikku V. K. (2002) Characterization of electron-beam modified surface coated clay fillers and their influence on physical properties of rubbers. Radiation Physics And Chemistry. 65: 627-640

[31] Tian M.; Cheng L.; Liang W.; Zhang L. (2005) The anisotropy of fibrillar silicate/rubber nanocomposites, Macromolecular Materials and Engineering. 290(7): 681-687

[32] Tian M.; Cheng L.; Liang W.; Zhang L. (2006) Overall properties of fibrillar silicate/styrene-butadiene rubber nanocomposites. Journal of Applied Polymer Science. 101(5): 2725-2731

[33] Kader M. A.; Kim K.; Lee Y. S.; Nah C. (2006) Preparation and properties of nitrile rubber/montmorillonite nanocomposites via latex blending, J. Mater. Sci. 41: 7341-7352

[34] Wang Y.; Zhang L.; Tang C.; Yu D. (2000) Preparation and characterization of rubberclay nanocomposites, J. Applied Polymer Science. 78: 1879-1883

[35] Zhang L.; Wang Y.; Wang Y.; Sui Y.; Yu D. (2000) Morphology and mechanical properties of clay/SBR nanocomposites, J. Applied Polymer Science. 78: 1873-1878

[36] Chakraborty S.; Sengupta R.; Dasgupta S.; Mukhopadhyay R.; Bandyopadhyay S.; Joshi M.; Ameta S. C. (2009) Synthesis and Characterization of Styrene Butadiene RubberBentonite Clay Nanocomposites, Polymer Engineering and Science, 49(7): 1279-1290

[37] Kim W. S.; Lee D. H.; Kim I. J.; Son M. J.; Kim W.; Cho S. G. (2009) SBR/Organoclay Nanocomposites for the Application on Tire Tread Compounds, Macromolecular Research. 17(10): 776-784

[38] Wang Y.; Zhang H.; Wu Y.; Yang J.; Zhang L. (2005) Preparation, structure and properties of a novel Rectorite/Styrene Butadiene copolymer nanocomposite, J. Applied Polymer Science. 96: 324-328

[39] Wang, Z. F.; Wang, B.; Qi, N.; Zhang, H. F.; Zhang, L. Q. (2005) Influence of fillers on free volume and gas barrier properties in styrene-butadiene rubber studied by positrons, Polymer. 46: 719-724 
[40] Rattanasom N.; Prasertsri S.; Ruangritnumchai T.; (2009) Comparison of the mechanical properties at similar hardness level of natural rubber filled with various reinforcingfillers. Polymer Testing. 28: 8-12

[41] Valadares L. F.; Leite C.A.P.; Galembeck F. (2006) Preparation of natural rubbermontmorillonite nanocomposite in aqueous medium: evidence for polymer-platelet adhesion, Polymer. 47: 672-678

[42] Karger-Kocsis J.; Wu C.M. (2004) Thermoset Rubber/Layered Silicate Nanocomposites. Status and Future Trends, Polym. Eng. Sci., 44(6): 1083-1093

[43] Varghese S.; Karger-Kocsis J. (2003) Natural rubber-based nanocomposites by latex compounding with layered silicates, Polymer, 44: 4921-4927

[44] Varghese S.; Gatos K.G.; Apostolov A.A.; Karger-Kocsis J. (2004) Morphology and Mechanical Properties of Layered Silicate Reinforced Natural and Polyurethane Rubber Blends Produced by Latex Compounding, J. Appl. Polym. Sci., 92: 543-551

[45] Stephen R.; Ranganathaiah C.; Varghese S.; Joseph K.; Thomas S. (2006) Gas transport through nano and micro composites of natural rubber (NR) and their blends with carboxylated styrene butadiene rubber (XSBR) latex membranes, Polymer, 47(3): 858-870

[46] Sharif J.; Zin W.; Wan M.; Mohd D.; Khairul Z.H.; Ahmad M.H. (2005) Preparation and properties of radiation crosslinked natural rubber/clay nanocomposites, Polym. Testing, 24, 211-217

[47] Sun Y.; Wo Y.; Jia D. (2008) Preparation and properties of natural rubber nanocomposites with solid state organomodified montmorillonite, Journal of Applied Polymer Science. 107: 2786-2792

[48] Wu Y.; Huang H.; Zhao W.; Zhang H.; Wang Y.; Zhang L. (2008) Flame retardance of MMT/rubber composites, Journal of Applied Polymer Science, 107: 3318-3324

[49] Hernandez M.; Carretero-Gonzalez J.; Verdejo R.; Ezquerra T. A.; Lopez-Manchado M. A.. (2010) Molecular Dynamics of Natural Rubber/Layered Silicate Nanocomposites As Studied by Dielectric Relaxation Spectroscopy. Macromolecules. 43(2): 643-651

[50] Galimberti M.; Senatore S.; Lostritto A.; Giannini L.; Conzatti L.; Costa G.; Guerra G. (2009) Reinforcement of diene elastomers by organically modified layered silicates. ePolymers. 57: 1-16

[51] Wang S.; Zhang Y.; Ren W.; Zhang Y.; Lin H. (2005) Morphology, mechanical and optical properties of transparent BR/clay nanocomposites, Polym. Testing. 24: 766-774

[52] Wang S.; Zhang Y.; Peng Z.; Zhang Y. (2005) New Method for Preparing Polybutadiene Rubber/Clay Composites, Journal of Applied Polymer Science. 98: 227-237

[53] Wang S.; Zhang Y.; Peng Z.; Zhang Y. (2006) Morphology and Thermal Stability of BR/Clay Composites prepared by a New Method, J. Appl. Polym. Sci. 99: 905-913

[54] Zhang H.; Wang Y.; Wu Y.; Zhang L.; Yang J. (2005) Study on Flammability of Montmorillonite/Styrene-Butadiene Rubber (SBR) Nanocomposites, J. Appl. Polym. Sci. 97: 844-849

[55] Sadhu S.; Bhowmick A. K. (2004) Preparation and properties of nanocomposites based on acrylonitrile-butadiene rubber, SBR and polybutadiene rubber, J. Polymer Science B. 42: 1573-1585 
[56] Morlat-Therias S.; Mailhot B.; Gardette J.; Da Silva C.; Haidar B.; Vidal A. (2005) Photooxidation of ethylene-propylene-diene/montmorillonite nanocomposites, Polym. Degrad. Stab. 90: 78-85

[57] Galimberti M., Cipolletti V., Giudice S. (2011) Morphology of rubber clay nanocomposites. In: Galimberti M. (Ed.), Rubber Clay Nanocomposites - Science, Technology and Applications, Wiley and Sons, New York, Chapter 7: 181-240.

[58] Joly S.; Garnaud G.; Ollitrault, R.; Bokobza L. (2002) Organically modified layered silicates as reinforcing fillers for natural rubber, Chemistry Of Materials. 14: 4202-4208

[59] Sadhu S.; Bhowmick A. K. (2004) Preparation and characterization of SBR based nanocomposites and study of their mechanical properties, Advanced Engineering Materials. 6(9): 738-742

[60] Sadhu S.; Bhowmick A.K. (2005) Unique rheological behaviour of rubber based nanocomposites, J. Polymer Science B. 43: 1854-1864

[61] Sadhu S.; Bhowmick A.K. (2005) Morphology study of rubber based nanocomposites by transmission electron microscopy and atomic force microscopy, J. Mater. Sci. 40: 1633-1642

[62] Sadhu S.; Bhowmick A.K. (2005) Effect of nanoclay on the dynamic mechanical properties of styrene butadiene and acrylonitrile butadiene rubber vulcanizates, Rubber Chemistry \& Technology.78: 321-335

[63] Maiti, M.; Sadhu, S.; Bhowmick, A. K. (2004) Effects of Heat and Pressure on Intercalation Structures of Isobutylene-Isoprene Rubber/Clay Nanocomposites. I. Prepared by Melt Blending, J. Polym. Sci. Part B: Polym. Phys. 42: 4489

[64] Galimberti M., Lostritto A., Spatola A., Guerra G., (2007) Clay delamination in hydrocarbon rubbers. Chemistry of Materials.19: 2495-2499

[65] Galimberti M., Senatore S., Conzatti L., Costa G., Giuliano G., Guerra G. (2009) Formation of clay intercalates with organic bilayers in hydrocarbon polymers. Polym. Adv. Technol. 20: 135-142

[66] Galimberti M., Giudice S., Cipolletti V., Guerra G. (2010) Control of Organoclay Structure in Hydrocarbon Polymers. Polymers for Advanced Technologies. 21: 679-684.

[67] Galimberti M., Riccio P., Giudice S., Citterio A., Riccò T., Pandini S., Ramorino G. (2009) Nanofillers for elastomers. Proceedings of the 176th Technical Meeting, Rubber Division of American Chemical Society, Pittsburgh, PA October 13-15.

[68] Austin J.R., Kontopoulou M. (2006) Effect of organoclay content on the rheology, morphology, and physical properties of polyolefin elastomers and their blends with polypropylene. Polym. Eng. Sci. 46: 1491-1501.

[69] Jeon H.S., Rameshwaram J.K., Kim G. (2004) Structure-property relationships in exfoliated polyisoprene/clay nanocomposites. J. Polym. Sci., Part B: Polym. Phys. 42: 1000.

[70] Jeon H.S., Rameshwaram J.K., Kim G., Weinkauf D.H. (2003) Characterization of polyisoprene-clay nanocomposites prepared by solution blending. Polymer 44: 57495758.

[71] Prasad R., Pasanovic-Zujo V., Gupta R.K., Cser F., Bhattacharya S.N. (2004) Morphology of EVA based nanocomposites under shear and extensional flow. Polym. Eng. Sci. 44: 1220-1230. 
[72] Vu Y.T., Mark J.E., Pham L.H., Engelhardt M. (2001) Clay nanolayer reinforcement of cis-1,4-polyisoprene and epoxidized natural rubber. J. Appl. Polym. Sci., 82: 1391-1403.

[73] Tian M., Qu C., Feng Y., Zhang L. (2003) Structure and properties of fibrillar silicate/SBR composites by direct blend process. J. Mater. Sci. 38: 4917-4924.

[74] Maiti M., Sadhu S., Bhowmick A.K. (2004) Brominated poly(isobutylene-co-paramethylstyrene) (BIMS)-clay nanocomposites: Synthesis and characterization. Journal of Polymer Science Part B: Polymer Physics 42: 4489-4502.

[75] Kader M.A., Lyu M.Y., Nah C. (2006) A study on melt processing and thermal properties of fluoroelastomer nanocomposites. Compos. Sci. Technol. 66: 1431-1443.

[76] Kim J.T., Oh T.S., Lee D.H. (2003) Morphology and rheological properties of nanocomposites based on nitrile rubber and organophilic layered silicates. Polymer International 52, 1203-1208.

[77] Wang X., Gao Y., Mao K., Xue G., Chen T., Zhu J., Li B., Sun P., Jin Q., Ding D., Shi A.C., (2006) Unusual Rheological Behavior of Liquid Polybutadiene Rubber/Clay Nanocomposite Gels: The Role of Polymer-Clay Interaction, Clay Exfoliation, and Clay Orientation and Disorientation. Macromolecules 39, 6653-6660.

[78] Lim S.K., Kim J.W., Chin I.J, Choi H.J. (2002) Rheological properties of a new rubbery nanocomposite: Polyepichlorohydrin/organoclay nanocomposites. J. Appl. Polym. Sci. 86: 3735-3739.

[79] Maiti M., Bhattacharya M., Bhowmick A.K. (2008) Elastomer Nanocomposites, Rubber Chemistry and Technology. 81:, 384-469.

[80] Verdejo R., Hernandez M., Bitinis N., Kenny J.M., Lopez-Manchado M.A. (2011) Vulcanization Characteristics and Curing Kinetic of Rubber/Organoclay Nanocomposites in: Galimberti M. (Ed.), Rubber Clay Nanocomposites - Science, Technology and Applications, Wiley and Sons, New York. Chapter 9: 275-304.

[81] Avalos F., Ortiz J.C., Zitzumbo R., López-Manchado M.A., Verdejo R., Arroyo M. (2008) Effect of montmorillonite intercalant structure on the cure parameters of natural rubber. European Polymer Journal. 44: 3108-3115.

[82] Lopez-Manchado M.A., Arroyo M., Herrero B., Biagiotti J. (2003) Preparation and characterization of organoclay nanocomposites based on natural rubber. Polymer International. 52: 1070-1077.

[83] Lopez-Manchado M.A., Arroyo M., Herrero B., Biagiotti J. (2003) Vulcanization kinetics of natural rubber-organoclay nanocomposites. Journal of Applied Polymer Science. 89: 1-15.

[84] Magaraphan R., Thaijaroen W., Ochakun R.L., (2003) Structure and properties of natural rubber and modified montmorillonite nanocomposites. Rubber. Chem. Technology. 76: 406- 418.

[85] Teh P.L., Mohd Ishak Z.A., Hashim A.S., Karger-Kocsis J., (2006) Physical properties of natural rubber/organoclay nanocomposites compatibilized with epoxidized natural rubber. Journal of Applied Polymer Science. 100: 1083-1092.

[86] Varghese J., Karger-Kocsis J. (2004) Journal of Applied Polymer Science. 91: 813-819.

[87] Mousa A., Karger-Kocsis J. (2001) Rheological and thermodynamical behavior of styrene/butadiene rubber-organoclay nanocomposites. Macromol. Mater. Eng. 286: 260266. 
[88] Lopez-Manchado M.A., Arroyo M., Herrero B. (2004) Organoclay-natural rubber nanocomposites synthesized by mechanical and solution mixing methods. Polymer International. 53: 1766-1772.

[89] Giannini L., Citterio A., Galimberti M. (2011) Chemistry of rubber/organoclay nanocomposites, in: Galimberti M. (Ed.), Rubber Clay Nanocomposites - Science, Technology and Applications, Wiley and Sons, New York, Chapter 5: 127-146.

[90] Takahashi S., Goldberg H.A., Feeney C.A., Karim D.P., Farrell M., O’Leary K., Paul D.R., (2006) Gas Barrier properties of butyl rubber /vermiculite nanocomposite coatings. Polymer. 47: 3083-93.

[91] Paul D.R., Robeson L.M. (2008) Polymer nanotechnology: Nanocomposites. Polymer. 49: 3187-3204.

[92] Jacob A., Kurian P., Aprem A.S. (2008) Transport properties of natural rubber latex layered clay nanocomposites. Journal of Applied Polymer Science. 108: 2623-2629.

[93] Li P., Wang L., Song G., Yin L., Qi F., Sun L. (2008) Characterization of highperformance exfoliated natural rubber/organoclay nanocomposites. Journal of Applied Polymer Science. 109: 3831-3838.

[94] Jacob A., Kurian P., Aprem A. S. (2007) Cure characteristics and mechanical properties of natural rubber-layered silicate nanocomposites. International Journal of Polymeric Materials. 56: 593-604.

[95] Gu Z., Song G., Liu W., Wang B., Li J. (2009) Preparation and properties of organomontmorillonite/cis-1,4-polybutadiene rubber nanocomposites by solution intercalation. Applied Clay Science. 45: 50-53.

[96] Hwang W. G., Wei K.H., Wu C.M. (2004) Mechanical, thermal and barrier properties of NBR/organosilicate nanocomposites. Polymer Engineering and Science. 44: 2117-2124.

[97] Liang Y.R., Cao W. L., Zhang X. B., Tan Y. J., He S. J., Zhang L. Q., 2009. Preparation and properties of nanocomposites based on different polarities of nitrile-butadiene rubber with clay. Journal of Applied Polymer Science 112: 3087-3094

[98] Donnet J.B., Custodero E., (2005) in The Science and Technology of Rubber Third Ed.; Mark, J.E.; Erman, B.; Eirich, F.R. Eds. Elsevier Academic Press Chapter 8: 367-400

[99] Wu Y., Jia Q., Yu D., Zhang L., (2004) Modeling Young's modulus of rubber-clay nanocomposites using composite theories. Polymer Testing 23 (2004) 903-909

[100] Schön F., Gronski W. (2003) Filler networking of silica and organoclay in rubber composites: reinforcement and dynamic mechanical properties. Kautschuk und Gummi Kunststoffe. 56: 166-171.

[101] Ramorino G., Bignotti F., Pandini S., Riccò T. (2009) Mechanical reinforcement in natural rubber/organoclay nanocomposites. Composites Science and Technology. 69: 1206-1211.

[102] Huber G., Vilgis T.A. (1999) Universal properties of filled rubbers: mechanisms for reinforcement on different length scales. Kautschuk und Gummi Kunststoffe. 52: 102-107.

[103] Payne A.R. (1962) The dynamic properties of carbon black loaded natural rubber vulcanizates. Part II. Journal of Applied Polymer. Scence. 21: 368-372

[104] Ramorino G., Bignotti F., Conzatti L., Riccò T. (2007) Dynamic and viscoelastic behavior of natural rubber/layered silicate nanocomposites obtained by melt blending. Polymer Engineering and Science. 47: 1650-1657. 
[105] Osman M.A., Ploetze M., Skrabal P. (2004) Structure and properties of alkylammonium monolayers self-assembled on montmorillonite platelets. Journal of Physics Chemistry B. 108: 2580-2588.

[106] Hrachová J., Komadel P., Chodák I. (2008) Effect of montmorillonite modification on mechanical properties of vulcanized natural rubber composites. Journal of Materials Science. 43: 2012-2017.

[107] Kim M.S., Kim G.H., Chowdhury S.R., (2007) Polybutadiene rubber/organoclay nanocomposites: effect of organoclay with various modifier concentrations on the vulcanization behavior and mechanical properties. Polymer Engineering Science. 47: 308-313.

[108] Hasegawa N., Okamoto H., Usuki A. (2004) Preparation and properties of ethylene propylene rubber (EPR)-clay nanocomposites based on maleic-anhydride modified EPR and organophilic clay. Journal of Applied Polymer Science. 93: 758-764.

[109] Teh P.L., Mohd Ishak Z.A., Hashim A.S., Karger-Kocsis J. (2004) Effects of epoxidized natural rubber as a compatibilizer in melt compounded natural-organoclay nanocomposites. European Polymer Journal. 40: 2513-2521

[110] Bhowmick A.K., Ganguly A., Maiti M. (2006) Factors influencing the morphology and the properties of clay-rubber nanocomposites. Kautschuk und Gummi Kunststoffe. 9: 437-446.

[111] Liang Y.R., Cao W.L., Zhang X.B., Tan Y.J., He S. J., Zhang L.Q. (2009) Preparation and properties of nanocomposites based on different polarities of nitrile-butadiene rubber with clay. Journal of Applied Polymer Science. 112: 3087-3094.

[112] Arroyo M., Lopez-Manchado M.A., Herrero B. (2003) Organo-montmorillonite as substitute of carbon black in natural rubber compounds. Polymer. 44: $2447-2453$.

[113] Jurkowska B., Jurkowski B., Oczkowski M., Pesetskii S.S., Koval V., Olkhov Y.A. (2007) Properties of montmorillonite-containing natural rubber. J. Appl. Polym. Sci. 106: 360-371.

[114] Kim M.S., Kim D.W., Chowdhury S.R., Kim G.H. (2006) Melt-compounded butadiene rubber nanocomposites with improved mechanical properties and abrasion resistance. J. Appl. Polym. Sci. 102: 2062-2066.

[115] Kojima Y., Usuki A., Kawasumi M., Okada A., Fukushima Y., Kurauchi T., Kamigaito O. (1993) Mechanical properties of nylon 6-clay hybrid. Journal of Materials Research 8: 1185-1189.

[116] Bokobza L., Leroy E., Lalanne V. (2009) Effect of filling mixtures of sepiolite and a surface modified fumed silica on the mechanical and swelling behavior of a styrenebutadiene rubber. Eur. Polym. J. 45: 996-1001.

[117] Maiti M., Sadhu S., Bhowmick A.K. (2005) Effect of Carbon Black on Properties of Rubber Nanocomposites. Journal of Applied Polymer Science 96: 443-451.

[118] Praaven S., Chattopadhyay P.K., Albert P., Dalvi V.G., Chakraborty B.C., Chattopadhyay S. (2009) Synergistic effect of carbon black and nanoclay fillers in styrene butadiene rubber matrix: development of dual structure. Composites: Part A. 40: 309-316.

[119] Gopi J.A., Patel S.K., Chandra A.K., Tripathy D.K. (2011) SBR-clay-carbon black hybrid nanocomposites for tire tread application. Journal of Polymer Research. 18: 1625-1634. 
[120] Galimberti M., Giannini L., D’Oria F., Lostritto A., Ponta T., Riccio P., Senatore S. (2008) Tailor made nanostructures for improved properties of tyre compounds. Proceedings from 174th Technical Meeting, Rubber Division of American Chemical Society, Louisville, KY (USA), October 14-16,

[121] Galimberti M., Giudice S., Coombs M., Giannini L., Buttafava A., Dondi D., Faucitano A., Pandini S., Riccò T., Bracco S., Cattaneo A., Sozzani, P., Conzatti, L., Cipolletti, V., 2010. Filler matrix interface characteristics and mechanical reinforcement in elastomeric nanocomposites. Proceedings of the Fall 178th Technical Meeting of the Rubber Division of the American Chemical Society, Inc. Milwaukee (WI) October 12-14.

[122] Cataldo F. (2007) Preparation and properties of nanostructured rubber composites with montmorillonite Macromolecular Symposia. 247: 67-77.

[123] Sridhar V., Shanmugharaj A.M., Kim J. K., Tripathy D.K. (2009) Optimization of Carbon Black and Nanoclay Filler Loading in Chlorobutyl Vulcanizates Using Response Surface Methodology. Polymer Composites. 30(6): 691-701

[124] Chattopadhyay P.K., Das N.C., Chattopadhyay S. (2011). Influence of interfacial roughness and the hybrid filler microstructures on the properties of ternary elastomeric composites. Composites: Part A. 1049-1059

[125] Malas A., Das C.K. (2012) Carbon black-clay hybrid nanocomposites based upon EPDM elastomer. Journal of Material Science. 47: 2016-2024.

[126] Galimberti M., Coombs M., Cipolletti V., Giannini L., Conzatti L., Riccò T., Mauro M., Guerra G. (2011) Nano and nanostructured fillers and their synergistic behavior in rubber composites such as tyres. Proceedings of the Fall 180th Technical Meeting of the Rubber Division of the American Chemical Society, Inc. Cleveland (OH) October 11-13.

[127] M. Galimberti, M. Coombs, V. Cipolletti, P. Riccio, T. Riccò, S. Pandini, L. Conzatti (2012) Accepted for publication on Applied Clay Science

[128] source: International Rubber Study Group

[129] source: The Freedonia Group

[130] Heinrich G., Herrmann W., Kendziorra N., Pietag T., Recker C. (2002). Rubber compound for tyre tread rubber. US 6818693 B2 to Continental

[131] Romani F., De Cancellis P. (2006) Studded Tyre WO 2006/002672 to Pirelli Tyre

[132] Zanzig, D.J., Yang X., Cohen M.P. (2010). Tyre with component comprised of a blend of polybutadiene rubber and composite of styrene/butadiene elastomer which contains exfoliated clay platelets. US 7,714,055 B2 to Goodyear.

[133] Galimberti M., Fino L., Verona M. (2003) Tyre for vehicle wheels with tread band of cap and base construction. WO 05/002883 to Pirelli Tyre

[134] Galimberti M., Fino L., Dessanti F. (2002) Tyre for two-wheeled vehicles. EP1597093 to Pirelli Tyre

[135] Giannini L., Fino L., Galimberti M. (2004) Tyre and crosslinkable elastomeric composition. WO 05/042278 to Pirelli Tyre

[136] Giannini L., Fino L., Galimberti M., Bizzi S. (2003) High performance tyre for vehicle wheels. EP 1677996 B1 to Pirelli Tyre

[137] Wada I., Ohara M., Uchino O., Koura T., Ezawa N., Kanoh M., Nakamura S. (2006) Rubber composition for inner liner. US 7.019.063 B2 to Bridgestone Corporation. 
[138] Miyazaki T. (2006) Rubber composition for inner liner. EP 1726620 A1 to Sumitomo Rubber Ind.

[139] Elspass W.C., Peiffer G.D., Kresge E.N., Wright P.J., Wang H.C. (1998) Tactoidal elastomer nanocomposites. US 5,807,629 to Exxon Mobil

[140] Elspass C.W., Peiffer D.G. (2000) Nanocomposite materials formed from inorganic layered materials dispersed in a polymer matrix. US 6,034,164 to Exxon Research and Engineering Company.

[141] Ishida, K., Fujiki, K., 2003. WO 03/087214 A1 to Bridgestone

[142] Elspass C.W., Peiffer D.G., Kresge E.N., Hsieh D.T., Chludzinski J.J., Liang K.S., (1999) Nanocomposite materials. US 5,883,173 to Exxon Research and Engineering Company

[143] Parker D.K., Larson B.K.F., Yang X. (2003) Preparation and use of a nanocomposite of elastomer and exfoliated clay platelets formed in situ within an elastomer host and articles of manufacture, including tires, having at least one component comprised thereof. EP 1321489 A1 to Goodyear Tyre and Rubber Company.

[144] Dias A.J., Tsou A. H., Chung D.Y.L. Weng W. (2005). Low permeability nanocomposites. US 2005/0027058 to Exxonmobil.

[145] Kresge E.N., Lohse D.J. (1997) Tire inner-liners comprising a solid rubber and a complex of a reactive rubber and layered silicate clay. US 5,665,183 to Exxonmobil

[146] Ajbani M., Geiser J.F., Parker D.K. (2003) Nanocomposite of elastomer and dispersion therein of intercalated clay prepared in an aqueous medium with funcional elastomer. US 2003/0144401 A1 to Goodyear Tyre and Rubber Company

[147] Gong C., Dias A.J., Tsou A. H., Poole B.J., Karp K.R. (2004) Functionalized Elastomer nanocomposite. WO 04/005387 to Exxonmobil.

[148] Grah M.D. (2004) Tire with improved inner liner. US 2004/0194863 A1 to Michelin

[149] Wang X., Fudemoto H., Hall J., Araki S., Hogan T., Foltz V., Sadhukhan P., Bohom, G.G.A. (2004) Method for clay exfoliation, compositions therefore, and modified rubber containing same. WO 058874 A1 to Bridgestone Corporation.

[150] Feeney C.A., Balzer, R.J. (1998) Barrier coating of an elastomer and a dispersed layered filler in a liquid carrier and coated compositions, particularly tires. WO 98/56598 to Michelin and Herberts Gmbh.

[151] Feeney C. A., Goldberg,H. A., Farrell M., Karim D. P., Oree K. R. (2006) US Patent 7,078453 to InMat Inc

[152] Feeney C. A., Goldberg H. A., Farrell M., Karim D. P., Oree K. R. (2006). US Patent $7,119,138$ to InMat Inc

[153] Feeney C.A., Farrell M., Tannert K., Goldberg H.A., Lu M., Grah M.D. (2001) US Patent 6,232,389. to InMat and Michelin Recherche et technique

[154] Feeney C.A., Farrell M., Tannert K., Goldberg H.A., Lu M., Grah M.D. (2000) US Patent 6,087,016 to InMat and Michelin Recherche et technique 